\title{
ACTITUDES DE YUCATECOS BILINGÜES DE MAYA Y ESPAÑOL HACIA LA LENGUA MAYA Y SUS HABLANTES EN MÉRIDA, YUCATÁN
}

\author{
Eyder Gabriel Sima Lozano \\ Universidad de Quintana Roo \\ Moisés Damián Perales Escudero \\ Universidad de Quintana Roo \\ Pedro Antonio Be Ramírez \\ Universidad Nacional Autónoma de México
}

\begin{abstract}
Resumen: Dentro del panorama general de estudios del maya yucateco, las actitudes linguíisticas hacia el mismo por parte de varios grupos de hablantes no han sido examinadas. Es así que este trabajo explora lo que un sector de la población yucateca bilingüe de maya y español de la ciudad de Mérida sostiene como actitudes hacia el idioma maya. Encontramos que las actitudes hacia la lengua son por lo general positivas; ésta tiene prestigio actualmente. Sin embargo, las actitudes que los hablantes bilingües perciben hacia los mismos hablantes son diferenciadas, algunas positivas y otras negativas. Se propone que las políticas se dirijan no sólo a incrementar el prestigio del idioma sino también de los hablantes.
\end{abstract}

Palabras Clave: Actitudes, bilingüies, lengua maya, Mérida.

ABSTRACT: Some linguistic attitudes towards Yucatec Maya held by various groups of speakers have not been examined. This paper explores the attitudes of Maya-Spanish bilinguals living in Merida toward Yucatec Maya. Our findings indicate that attitudes toward Yucatec Maya are generally positive; the language is currently seen as prestigious. However, the attitudes that bilinguals perceive toward their in-group are both positive and negative. We propose that language policy and planning should explicitly attempt to increase the prestige of the speakers and not only of the language.

KEYwords:: attitudes, bilingual, Mayan language, Merida.

RECEPCIÓN: 21 de mayo de 2013.

ACEPTACIÓN: 9 de agosto de 2013. 



\title{
ACTITUDES DE YUCATECOS BILINGÜES DE MAYA Y ESPAÑOL HACIA LA LENGUA MAYA
Y SUS HABLANTES EN MÉRIDA, YUCATÁN
}

\author{
Eyder Gabriel Sima Lozano \\ Universidad de Quintana Roo \\ Moisés Damián Perales Escudero \\ Universidad de Quintana Roo \\ Pedro Antonio Be Ramírez \\ Universidad Nacional Autónoma de México
}

"Antes la maya estaba bien tirada, pero ahora hasta en la tele salen", según diversos informantes

\section{Introducción}

Actualmente, los estudios de actitudes linguísticas han cobrado importancia pues permiten observar el contacto de lenguas, así como la vitalidad, el mantenimiento y el desplazamiento de un idioma y la toma de decisiones para las políticas del lenguaje (Fishman, 1974, 1979, 1991; McConnell, 1991; Zimmermannn, 1999). En el ámbito de lenguas mexicanas tenemos algunos ejemplos como los trabajos de Hamel y Muñoz (1988); Castillo Hernández (2007); Terborg y García Landa (2011); Trujillo Tamez (2011); Rico Lemus (2011), y Neri (2011). Para el contexto del maya yucateco encontramos los estudios de Pfeiler (1997, 1999); Pfeiler y ZámiŠová (2006); Sánchez Arroba (2009); Canché Teh, Pfeiler y Carrillo Carreón (2010); Sima Lozano (2011); así como el de la relación de maya español e inglés tratado por Hernández Méndez y Sima Lozano (2012).

Desde la sociolinguística, disciplina que teoriza el concepto de actitud, se generan retos para la planificación del lenguaje, pues al revisar las actitudes de los hablantes, el diseño de estrategias para la preservación del idioma es más eficaz que si se procede sin ningún conocimiento previo. En ese sentido, el objetivo de este trabajo es analizar las actitudes de yucatecos bilingües de maya y español que habitan en la ciudad de Mérida respecto a la lengua maya y hacia ellos como hablantes bilinguies. ${ }^{1}$ Seleccionamos este espacio porque corresponde a la capital

\footnotetext{
${ }^{1}$ Las formas de referirse a la lengua según los hablantes bilingües son "la maya" y "lengua maya". Algunos monolingüies de español usan: "el maya", mientras que el Instituto Nacional de Lenguas Indígenas, INALI (2008), nombra al idioma como "maya yucateco". En este trabajo no seguiremos alguna forma particular, más bien otorgamos voz, según lo que expresan los hablantes y el mismo INALI. Sin embargo, este tema podría ser una investigación futura que se propone realizarse.
} 
del estado de Yucatán, a donde llega un número importante de habitantes provenientes de todas las regiones socioeconómicas de la entidad, y al mismo tiempo es la mayor urbe de la región peninsular.

Los estudios anteriores que han analizado propiamente actitudes hacia el maya yucateco en el estado de Yucatán se han realizado con poblaciones rurales (Jiménez Peraza, 1982; Pfeiler, 1993; Alvarez Murillo, 2008) o con jóvenes (Durán Caballero y Sauma Castillo, 2003), en tanto que el presente artículo abarca una muestra etaria más diversa y urbana. La única investigación en el mismo contexto (Sima Lozano, 2011) analiza las actitudes de los monolingüies de español de Mérida hacia la lengua maya y los hablantes monolingües de maya, y encuentra una valoración positiva hacia la lengua, pero negativa hacia los mayahablantes. Sin embargo, no reporta las actitudes de los yucatecos bilinguies de maya y español hacia sí mismos. ${ }^{2}$

A partir de estos antecedentes, el trabajo plantea las siguientes preguntas: ¿cuáles son las actitudes de los yucatecos bilinguies de maya y español de la ciudad de Mérida hacia la maya y hacia los propios hablantes bilingües? ${ }^{3}$ Tras encontrar, en general, actitudes positivas que contrastan con las negativas halladas por estudios previos (v. gr. Cazés, 1990), planteamos la segunda pregunta: ¿por qué se han modificado las actitudes de los yucatecos bilingüies de maya y español?

Una de las razones por las que presentamos el trabajo es el contraste entre la mejora en las actitudes y el número de hablantes de la lengua maya que decrece notablemente. ${ }^{4}$ En 2005, el Instituto Nacional de Estadística y Geografía, INEGI, reportó que el $33.3 \%$ de la población yucateca hablaba la maya, mientras que en 2010 el mismo instituto aseguró que solamente el $27.5 \%$ era hablante de maya (INEGI, 2005, 2010). ${ }^{5}$ Por el contrario, gran parte de la población que participa en este estudio sostiene que la maya tiene valor y prestigio.

En el análisis destacamos cuatro categorías de expresión de las actitudes desde una perspectiva émica: bilingüismo, legitimidad de la variante, visión del pasado y visiones recientes. En general, los hablantes bilingües de mayor edad perciben una mejoría en el estatus de la lengua, pero los hablantes bilinguies jóvenes perciben actitudes diferenciadas hacia la lengua y hacia ellos mismos, las

\footnotetext{
2 Vale la pena resaltar brevemente el trabajo de López Santillán (2011) que, desde una perspectiva antropológica centrada en la etnicidad, obtuvo 34 relatos de vida de profesionistas mayas en la ciudad de Mérida, concluyendo que el sentimiento de pertenencia a lo maya peninsular está presente en la vida de los sujetos del análisis, entre cuyos aspectos se destaca la lengua maya.

${ }^{3}$ Por "actitudes de los hablantes" queremos decir tanto las actitudes que estos hablantes perciben en los exogrupos de su entorno respecto a sí mismos y su lengua, así como las actitudes propias del endogrupo al cual se adscriben, es decir, los mayahablantes bilingües.

${ }^{4}$ Mossbrucker (2001) sostiene que el uso de la lengua maya ya no es común en la vida diaria de la población de Mérida como lo era hace 30 años, en tanto Pfeiler (1997) señala el decrecimiento desde la década de los setenta. Briceño Chel $(2010,2012)$ indica que actualmente sólo el $2 \%$ de la población infantil maya está aprendiendo la lengua.

${ }^{5}$ En la página del INEGI (2010) se indica que la población de Yucatán que habla una lengua indígena es del 30\% (incluye maya y otras lenguas), pero si descontamos el número de hablantes que no corresponden al maya yucateco el resultado es de un $27.5 \%$.
} 
cuales pueden explicarse por su estatus socioeconómico, pero también problematizarse desde una consideración del rol de las políticas públicas en el estatus de los hablantes.

En la parte final presentamos algunas reflexiones críticas con el fin de revisar el alcance de las políticas del lenguaje hacia el yucateco bilinguie de maya y español, pues el beneficio de tales políticas ha creado actitudes positivas hacia el idioma, pero cuando se trata del hablante, se reportan actitudes diferenciadas y éste aparece con menor valor. El considerar los diversos aspectos que otorgan prestigio o estigma hacia la lengua y quien la habla, según el contexto de la interacción, será de mucha importancia para crear estrategias que propicien una valoración real de los hablantes de maya en la ciudad de Mérida y en el estado de Yucatán.

\section{Marco teórico}

Para el estudio de las actitudes existen tres perspectivas metodológicas, según Bouchard Ryan, Giles y Sebastian (2000). La primera es el análisis de contenido del tratamiento societal que observa cómo se tratan las lenguas públicamente y las políticas gubernamentales hacia ellas. La segunda es la postura conductista que señala que las actitudes se observan en el medio, por lo que se usan la entrevista, la observación participativa o indirecta y cuestionarios, así como experimentos de interacción entre hablantes. La tercera posición es la mentalista, la cual dice que las actitudes están guardadas en la mente de los hablantes, por lo que las técnicas del matched-guise y del diferencial semántico son las preferidas. ${ }^{6}$

Cabe entonces señalar que la primera y la segunda posturas forman parte de nuestro trabajo, pues nos centramos fundamentalmente en lo que manifiestan los hablantes a través de las entrevistas, para después considerar los hallazgos a la luz de las políticas públicas hacia la lengua, dado que ello es el interés que guía este documento.

En cuanto a la definición de actitud lingüística que guía este trabajo, la explicitamos como un conjunto de valores que un sector de población le concede a una lengua o sus variantes, motivado por la situación temporal en la que se encuentra el idioma, ya que las actitudes cambian conforme a las diversas circunstancias por las que atraviesan las lenguas.

La definición propuesta, entonces, permite ubicar las actitudes en el contexto de los acontecimientos actuales por los que franquean la lengua y la cultura mayas, pues con el paso del tiempo pueden modificarse, es decir, no son fijas

\footnotetext{
${ }^{6}$ Como bien se dijo, aunque el estudio parte de la primera y segunda postura, eso no quiere decir que creamos que la tercera no tenga validez. Elegimos presentar datos de políticas públicas y entrevistas por cuestiones de espacio, pero hemos aplicado otras técnicas como el matched-guise con los mismos informantes en otros trabajos.
} 
y permanentes, no son creencias arraigadas en los hablantes. Es por eso que dicha definición permite argumentar que las actitudes actuales de los hablantes mayas de la ciudad de Mérida hacia el maya yucateco son parte de una moda cuya permanencia o desaparición podrá determinarse sólo después de algún tiempo.

\section{La muestra y metodología de análisis}

Para la realización de este trabajo seleccionamos a la población que habita en colonias del sur, oriente y centro, así como de lugares del poniente de la capital yucateca y que forman parte de un estudio etnográfico más amplio realizado durante el 2009. La información que aquí se analiza proviene de una muestra de veinticinco entrevistas semidirigidas que se obtuvieron al visitar a las personas en sus hogares o en sus negocios particulares. Las variables sociales fueron las siguientes: bilingüies de maya y español, género, edad, actividad y colonia en la que habitan. La variable de clase social se dedujo a partir de la visita a los entrevistados en sus hogares, donde se observaron las condiciones socioeconómicas que los caracterizan, así como las actividades que realizan. Algunas de éstas evidencian el tipo de ingresos percibidos.

Asimismo, la edad de los entrevistados es diversa, desde jóvenes y adultos, hasta personas de la tercera edad. Se eligió una población etaria diversa con el fin de observar si la variación manifestaba algún cambio en relación a las actitudes hacia la lengua maya. En la tabla 1 proporcionamos una caracterización de los participantes, quienes son bilinguies de maya y español.

El trabajo se enmarca en la investigación cualitativa, a través del trabajo de campo realizado, en donde las respuestas expresadas por los informantes se analizaron desde sus propios puntos de vista, de manera inductiva (Barragán Trejo, 2009; Hernández Sampieri, Fernández Collado y Baptista Lucio, 2006). Cada uno de los cuestionamientos aplicados en la entrevista abrió un conjunto de temas cuyo valor semántico fue determinante para realizar las agrupaciones.

La forma en la que se procedió para obtener las categorías fue a partir de la observación de similitudes en las respuestas de los informantes. Se identificaron temas que tienen una relación, es decir, un vínculo significativo que los une (Barragán Trejo, 2006). Antes de pasar a la presentación y discusión de estas categorías, incluimos una descripción del contexto de la investigación y una semblanza de una de las informantes, doña Pastora, cuyo caso recapitula las categorías actitudinales halladas en el discurso de otros informantes.

\section{Un caso epítome: doña Pastora}

Entre el universo que constituye este estudio, sobresale el caso de una mujer yucateca bilinguie de maya y español, Pastora, de 84 años, quien destaca en su 


\begin{tabular}{|c|c|c|c|c|}
\hline Género & Edad & Clase social & Actividad & Colonia \\
\hline Masculino & 85 & Baja & Ejidatario-pensionado & San Marcos Nocoh \\
\hline Femenino & 84 & Baja & Ama de casa & San Marcos Nocoh \\
\hline Masculino & 77 & Baja & Ejidatario-pensionado & María Luisa \\
\hline Femenino & 82 & Media & Vendedora de hamacas & San Marcos Nocoh \\
\hline Masculino & 65 & Baja & Ejidatario & Francisco I. Madero \\
\hline Femenino & 61 & Baja & Ama de casa & San Marcos Nocoh \\
\hline Femenino & 80 & Baja & Ama de casa & San Marcos Nocoh \\
\hline Masculino & 54 & Baja & Albañil & Sambulá \\
\hline Femenino & 55 & Baja & Ama de casa & San Marcos Nocoh \\
\hline Masculino & 53 & Baja & Obrero & San Marcos Nocoh \\
\hline Masculino & 40 & Baja & Despachador & Obrera \\
\hline Femenino & 43 & Media & Ama de casa & Morelos \\
\hline Femenino & 56 & Baja & Intendente & Juan Pablo II \\
\hline Masculino & 39 & Baja & Vendedor de tortillas & San Marcos Nocoh \\
\hline Masculino & 37 & Baja & Vendedor de semillas & San Marcos Nocoh \\
\hline Femenino & 52 & Baja & Ama de casa & Centro \\
\hline Masculino & 33 & Baja & Albañil & San Marcos Nocoh \\
\hline Masculino & 32 & Media & Dueño de una tienda & Morelos \\
\hline Masculino & 33 & Media & Docente & Pensiones \\
\hline Masculino & 29 & Media & Docente & Centro \\
\hline Femenino & 21 & Media & Estudiante & Sambulá \\
\hline Femenino & 17 & Baja & $\begin{array}{c}\text { Vendedora de } \\
\text { periódicos }\end{array}$ & Sambulá \\
\hline Masculino & 20 & Media & Encuestador & Yucalpetén \\
\hline Masculino & 19 & Media & Estudiante & Obrera \\
\hline Masculino & 18 & Baja & Albañil & Centro \\
\hline
\end{tabular}

TABLA 1. Características de los participantes. 
testimonio algunas actitudes del pasado pero también del presente de la lengua maya. Asimismo, sus ideas confirman la noción de actitud lingüística aquí propuesta, la temporalidad de la lengua, pues la informante afirma: "Porque hoy la maya está así" (25). Esta frase tiene mucha importancia con lo que actualmente se observa hacia la lengua maya en la ciudad de Mérida y en la entidad. Cabe decir que el contenido de la entrevista y las respuestas de doña Pastora sintetizan los demás datos de los informantes, es decir, es una representación de la población estudiada. A continuación presentamos parte de la entrevista con la señora Pastora:

Claves: P (doña Pastora), E (entrevistador).

Se enumeran cada turno del entrevistador y de la informante.

1. - P. Mi mamá habla en maya, mi abuelita, pero de antes, casi no hablaban a los niños en maya por su idea de los señores grandes, porque la pobre maya lo tenía así un poco bajo, como que lo, a un lado lo ponen, entonces fuimos creciendo, creciendo y pos así aprendí maya y aprendí un poco de español.

2. - E. ¿Entonces usted cree que no habla maya completo?

3. - P. No, no hablo maya completo.

4. - E. ¿Por qué?, ¿quiénes hablan maya completo?

5. - P. Pos los muy antiguos, porque hay tantas palabras distintas que no, yo no lo sé, en los pueblos así, más los antiguos sí saben la legítima maya, nosotros fue cambiando, cada generación que se levantaba fue el cambio de hablar.

6. - E. ¿Hace cuántos años que vive usted aquí en Mérida?

7. - P. $[\ldots]$ Como 50 años.

8. - E. ¿Por qué se vino a vivir a Mérida?

9. - P. Porque me casé y había trabajo a mi esposo y nos bajamos aquí en Mérida, aquí buscamos nuestra vida.

10. - E. ¿Y en aquel tiempo en que se vino a vivir a Mérida, qué pensaba la gente de Mérida sobre los que hablaban maya?

11. - P. Pues lo que venían así, casi no, no se entienden, los vendedores que estaban aquí en Mérida, tenían que esforzarse en hablar maya para que hable los señores a comprar $[\ldots]$

12. - E. ¿Y los que no hablaban maya, o sea, los que hablaban solamente castellano, qué pensaban sobre cuando, cuando conocían a alguien que hablaba maya?

13. - P. Pues nos despreciaban va, si nos despreciaban, si porque hablamos en maya.

14. - E. ¿Cómo lo manifestaban, hacían algún gesto?

15. - P. Sí, así, waye', maaya, chen mayeero, chen indio, dicen, ahh.

16. - E. Mayero, indio, decían. 
17. - P. Son mayeros, son indios, son de pueblos, de pueblos, mmm [...]

18. - E. ¿Sus hijos saben hablar maya?

19. - P. No pos, no saben, sólo entienden.

20. - E. ¿Por qué no aprendieron?

21. - P. Porque no les enseñé.

22. - E. ¿Y por qué no les enseñó?

23. - P. Creo que por orgullo, no sé, no sé, es lo que no sé, porque en el colegio, en el colegio también puro español enseñaban, nadie hablaba en maya, sólo algunos profesores te hablaban en maya, algunos, algunos te decían algo en maya, pero puro español se hablaba, puro español, desde el nene más chiquitito le enseñan a hablar en español. [...]

24. - E. ¿Y actualmente, usted cree que fue la mejor decisión que no les enseñara maya a sus hijos, o actualmente si volviera a tener a sus hijos de pequeños les enseñaría maya?

25. - P. Ah claro que sí, porque hoy la maya está así.

26. - E. ¿Cómo así?

27. - P. ¿Cómo te diré? ¿Cómo te diré? ¿Cómo te puedo?

28. - E. ¿Tiene prestigio?

29. - P. Ándale, ajá.

30. - E. ¿Tiene valor?

31. - P. Tiene valor, ándale, tiene valor, la maya ahorita tiene valor, sí.

32. - E. ¿Y por qué cree que tenga valor actualmente?

33. - P. Pues, porque, porque se está acabando toda la humanidad de los antiguos, pues antes de que se acabe, creo que se dieron cuenta la autoridad o los profesores o no sé, y entonces ahí vienen, ay aprecian la maya, ajá.

34. - E. ¿Entonces actualmente la gente ha cambiado su punto de vista sobre la maya?

35. - P. Ajá, sí, ahora aprecian la maya, ahora todos quieren aprender maya, todos, aunque sea, como sea, como de lado se dicen, quieren hablar de maya, hablan maya, todos, hasta los doctores, mjum.

Como se puede observar en la precedente interlocución, la señora Pastora remite al pasado, ya que señala cómo su mamá y su abuela hablaban en maya. A pesar de que creció en una comunidad del interior del estado de Yucatán, ella expresa que la lengua maya no fue enseñada con mucho entusiasmo a los niños: "casi no hablaban a los niños en maya" (1), esto lo atribuye al bajo prestigio de la lengua en aquel momento (1). Afirma que en el proceso de su crecimiento (1) escuchaba en su comunidad las dos lenguas: maya y español, idiomas que aprendió con el paso del tiempo. Posteriormente afirma que no habla "la maya completa", es decir, "legítima" (3), y señala que quienes lo hacen son los "muy antiguos" (5). Luego nos indica la necesidad que ella y su esposo tuvieron de viajar a la capital yucateca con el fin de buscar mejores oportunidades y hacer su vida en pareja (9). 
Las siguientes actitudes de doña Pastora exponen cómo la gente de Mérida percibió a los mayahablantes hace 50 años: "nos despreciaban" (13), "son mayeros, son indios, son de pueblos" (17), según decía la gente de la ciudad de Mérida a los hablantes de la lengua maya. Posteriormente, relata lo que sucedió con sus hijos en la ciudad de Mérida en cuanto a la transmisión del idioma. Las últimas líneas se centran en el prestigio y valor de la lengua maya en estos momentos. A continuación, desglosamos las categorías actitudinales expresadas en la entrevista.

\section{Bilingüismo: "Hablo maya y hablo español"}

Es común que las dos lenguas en contacto, maya y español, se encuentren desde fases tempranas de aprendizaje en los hablantes, de tal forma que estamos en una situación de bilinguiismo social, dado que los porcentajes de uso de maya y de español son de proporciones amplias en la población yucateca de la ciudad de Mérida.

Al respecto, Silva-Corvalán (2001) hace la diferencia entre bilingüismo social y de grupo. El primero es el que existe cuando grupos numerosos de individuos hablan dos lenguas, mientras que el segundo está limitado a un grupo pequeño de individuos que se vincula por lazos familiares o de trabajo. En la ciudad de Mérida el grupo de hablantes bilinguies de maya y de español representa el 8.9\% de la población, según el INEGI (2011), pero puede implicar un número mayor si se consideraran a los que aseguran entender la maya, pero no hablarla. Así pues, es una situación natural para un sector de población de la metrópoli yucateca el afirmar que conocen las dos lenguas, como se muestra en el siguiente testimonio:

Pues desde chica, aprendí, desde chica porque mis papás hablaban maya, sí puro maya, hasta ya grande aprendí español en la escuela. (Femenino, 61 años)

Como podemos observar, para los yucatecos bilingües de maya y español en cuestión, es común que primero aprendieron la maya y posteriormente el español. En la mayoría de los casos el idioma maya es su primera lengua y generalmente son los padres quienes lo transmiten a sus hijos. No obstante, existen excepciones a esta regla, como se abordará más adelante.

\section{Legitimidad de la variante: "Yo no sé la legítima maya"}

Entre los yucatecos bilinguies de maya y español de la urbe meridana existe la creencia de que ellos no hablan una maya legítima, sino una mezcla entre español y maya. Otros señalan que la lengua maya legítima se habla en el oriente de 
Yucatán y en Quintana Roo, reconociendo de esa forma que existen variantes de la lengua maya. Al respecto, Pfeiler (1998) ha señalado la existencia de dos formas que los hablantes establecen para nombrar dicha lengua, xe'ek' maya y hach maya.

La variante nombrada como maya yucateco, que se emplea en toda la península de Yucatán, suele ser homogénea, pero esto no quiere decir que no existan diferencias. El xe'ek' y la hach son las formas más generales que se nombran entre los hablantes, pero existen otras denominaciones que usa la población para referirse al idioma maya que ellos consideran auténtico o mezclado: "maya pura", "maya antigua”, "maya verdadera”, "maya legítima”, "maya amestizada”, "maya mezclada", "uayeismo".

Los yucatecos bilinguies de maya y español en Mérida sostienen que la hach maya existió durante los tiempos antiguos o se habla en algunos lugares de la Península, como el oriente. Parafraseando el título del trabajo de Bright (2000), podría pensarse que los hablantes dicen cosas que creen pero que no son ciertas; sin embargo, es legítimo para la comunidad ver a la lengua de ese modo, pues son sus puntos de vista y son ellos los que pueden arrojar más luz sobre el conocimiento de estas variantes de la maya.

Porque hay dos tipos de maya, hay el tipo de maya original, original, hay el maya mestizo mezclado, mezclado. (Masculino, 38 años)

Así, este conjunto de actitudes imaginarias es parte de una serie de formas que suponen los hablantes acerca de la esencia de la lengua maya en cuanto a su pureza y su contacto con el español y que ha generado para ellos una maya mezclada, tal como se expresa en el testimonio anterior.

\section{Visión del pasado: "Son mayeros"}

En esta categoría los hablantes de maya de la tercera edad se percibieron despreciados ${ }^{7}$ por los habitantes de Mérida cuando arribaron a la ciudad en décadas pasadas. Indicaron que, por el hecho de ser originarios de las localidades del interior que nombran como "pueblos", 8 fueron llamados despectivamente mayeros o indios:

Pues eso nos dice indio, porque no sabemos hablar en castellano, nos dicen: son mayeros, son del pueblo, nos, bueno, ellos lo ven porque somos del pueblo, no sabemos hablar en español. (Masculino, 85 años)

\footnotetext{
${ }^{7}$ Rodríguez (2000: 11) dice que "la gente bien desprecia a los mestizos urbanos y éstos hacen lo propio con los indígenas de los pueblos llegados a la urbe. Quien esté más cercano a las raíces indígenas se expondrá más al desprecio" (énfasis nuestro).

${ }^{8} \mathrm{Al}$ respecto, Cazés (1990: 593) afirma que "los grupos mexicanos se caracterizan también porque sus integrantes tienen como referencia ideológica paradigmas culturales de tipo rural. Esto es cierto aun cuando sean muy fuertes las tendencias a la migración hacia zonas preferentemente urbanas".
} 
Por lo anterior, el mayahablante recurrió a diversas estrategias para ocultar su identidad. Una de ellas fue que en el momento en que sabía que ingresaba a Mérida inmediatamente dejaba de hablar en lengua maya, y al mismo tiempo se produjo una negación de la identidad como consecuencia de la presión del español y el estilo de vida urbano. Aquí vemos cómo las actitudes de los hablantes de maya en décadas pasadas generaron lo que Cazés (1990) denomina opresión lingüística, verificada en el siguiente testimonio:

Pues la mayoría de la gente eran mayeros, como era poco la gente que había en la ciudad, en la colonia, casi todos son mayeros, casi todos hablaban, claro que a nosotros nos inculcaban siempre no, no hablar la maya, no, pero uno aprende a través de que uno está dentro de ellos. (Masculino, 65 años)

Sin embargo, es necesario señalar brevemente que durante la Colonia y en el siglo xIx, la lengua maya fue hablada mayoritariamente en Yucatán incluso entre la gente de clase alta del norte de la ciudad de Mérida, de tal forma que la maya era hablada por un amplio sector de población (Arzápalo, 1997). Entonces, ¿qué motivó a que entre 1930 y 1950 la gente yucateca bilinguie de maya y español dejara de hablar la lengua? La respuesta tiene que ver con las políticas del lenguaje posteriores a la Revolución, pues lo que se proponía era la castellanización del indígena, entre ellos el maya. ${ }^{9}$ La ya mencionada señora Pastora lo confirma cuando dice:

porque en el colegio, en el colegio también puro español enseñaban, nadie hablaba en maya, sólo algunos profesores te hablaban en maya, algunos, algunos te decían algo en maya, pero puro español se hablaba, puro español, desde el nené más chiquitito le enseñan a hablar en español. (Femenino, 85 años)

De esa forma, ella nota cómo en las instituciones educativas en las que acudieron sus hijos el español era la lengua predominante. Aunque existían algunas expresiones en maya, el español era la lengua que todos los actores de la educación emplearon hacia los estudiantes. No obstante, la oposición era más que evidente.

Pero lo malo es como le digo, en el colegio nos prohibieron hablar maya. (Femenino, 43 años)

\footnotetext{
${ }^{9}$ Cabe aclarar que en la relación de lo indígena con lo maya es un debate entre diversas posturas antropológicas, pues algunos autores sostienen que el maya yucateco es un indígena, en tanto otros, como Castañeda (2004), ponen en duda esa categorización, ya que asegura que es común encontrar en el territorio yucateco personas que afirman con mucho orgullo: "soy maya, pero no soy indígena". De tal forma que resulta de una gran complejidad definir al maya yucateco como un grupo étnico, según Castañeda (2004) y Be Ramírez (2011), siendo este último quien define la identidad, para este caso, como situada. Sin embargo, no se niega que muchos hablantes de maya se definían a sí mismos como indios, según sostiene el hablante masculino de 85 años a quien se ha citado al principio de este apartado. Como vemos, la situación es compleja y heterogénea.
} 
Para esta informante, no sólo predominó el español sobre la maya, sino que también menciona una acción negativa sobre el idioma maya: la prohibición de hablarlo en las escuelas. Por lo que, en décadas pasadas, el proceso de homogeneización y desarrollo del país se inclinó hacia la castellanización. Esto es lo que afectó el uso de la maya en las urbes como Mérida, dando como resultado la actitud hacia el idioma maya donde se dice que en la capital yucateca no se hablaba la maya, "aquí no se habla la maya, en los pueblos se habla", tal como refieren diversos informantes.

\section{Visiones recientes: "Porque hoy la maya está así"}

Diversas percepciones existen entre los hablantes de maya y español sobre la forma en la que ellos y la lengua son vistos actualmente en la ciudad de Mérida. Hay quienes, como doña Pastora, aseguran que la lengua maya es reconocida, y ellos también lo son por hablarla. En contraste, existen también aquellos que se sienten despreciados si dan a conocer su lengua ante los monolingüies de español. Lo anterior viene a afirmarse con lo que López Santillán (2011: 201) refiere sobre la estigmatización acerca de ser maya y, por lo tanto, sobre "que algunos mayas no quieran hablar la lengua vernácula”.

Lo cierto es que las visiones recientes han modificado las actitudes de los hablantes bilingüies de maya y español hacia sí mismos. El valor de la maya no es igual que en el pasado, como cuando los informantes expresaron que "la lengua estaba tirada", pero que actualmente "hasta en la tele salen", esto, para representar que es tanto el valor del idioma en la actualidad que se puede observar a personas en medios electrónicos hablando en maya, lo cual genera una situación de prestigio para la población maya de Mérida.

La reflexión que la señora Pastora hace sobre el valor actual de la lengua maya está fundamentada en una idea que puede funcionar como metáfora: "se está acabando toda la humanidad de los antiguos" (33), para significar que las personas mayores están muriendo y como consecuencia de ello intervienen "la autoridad o los profesores o no sé, y entonces ahí vienen, ay aprecian la maya" (33).

Aunque la frase "se está acabado toda la humanidad de los antiguos" pareciera un imaginario, el hecho es que la señora Pastora conduce a una etnografía del idioma maya en la ciudad de Mérida, pues observa que actualmente existe menos gente que habla maya, aunque en este caso tendríamos que analizar el tema desde una perspectiva del desplazamiento y mantenimiento. En contraste, lo que sí está en apogeo en la Península de Yucatán, y particularmente en la ciudad de Mérida, son las actitudes que le conceden valor y prestigio al idioma maya, lo cual es una discrepancia, pues, mientras decrecen los hablantes de la lengua maya, los puntos de vista positivos hacia ella se aceleran notoriamente. Así, ella observa que hay un cambio de actitudes hacia la lengua maya en estos momentos. 
Por lo anterior, este planteamiento nos dirige a la pregunta ¿por qué se han modificado las actitudes de los yucatecos bilingüies de maya y español? Las actitudes hacia el maya yucateco argumentadas por la señora Pastora tienen su punto de origen en las políticas linguíísticas. Esto lo expresa cuando refiere a "la autoridad o los profesores [...] ahí vienen". Aquí concordamos con lo que plantea, pues efectivamente se han creado políticas linguíísticas hacia la lengua maya en los últimos 20 años en ámbitos educativos y turísticos (Durán Caballero y Sauma Castillo, 2003; Pfeiler y ZámiŠová, 2006; Villanueva, 2008).

Al respecto, Ager (2001) explica que la planificación linguíística está dividida en tres campos de aplicación: estatus, corpus y planificación de la adquisición. El estatus modifica el prestigio de una lengua dentro de la sociedad, frecuentemente transformado por los usos y funciones que los individuos y grupos asignan a esa lengua en una comunidad. En este caso, las políticas linguiísticas han incidido para que los hablantes bilingües de maya y español de la ciudad de Mérida perciban su lengua como valiosa. Sobre el corpus, éste aparece cuando las comunidades estandarizan su lengua en la parte oral y escritural, la modernizan o la renuevan. El problema de cómo escribir la lengua maya es un proceso que afecta en este caso al idioma.

En cuanto al aspecto de la planificación de la adquisición, existen en la ciudad de Mérida y en el estado de Yucatán diversos tipos de programas para la enseñanza del idioma maya. Esto ha traído como consecuencia que la gente genere actitudes en relación con la educación y expresen ideas como: "ahora hasta en las escuelas se enseña maya, es obligatorio"; "Si vas a un pueblo, necesitas saber maya; claro, así nadie te engaña"; "Pero ahora hasta en la tele salen"; "Esa señora sólo porque sabe la maya sale en la tele, qué tonta fui que no aprendí la maya" (Sima Lozano, 2010).

Lo anterior entonces es consecuencia de las políticas que los gobiernos estatales de Yucatán generaron hacia el idioma maya, tal como asegura Villanueva (2008), quien lo ejemplifica al afirmar que, durante el periodo del gobierno estatal de Patricio Patrón Laviada (2001-2007), la cultura y lengua maya se pusieron de moda a nivel internacional, nacional y local. Aunque podríamos señalar que, desde la administración de Víctor Cervera Pacheco (1995-2001) y durante el mandato de Ivonne Ortega Pacheco (2007-2012), ambos de corte paternalista, ya estaba poniéndose en marcha este proyecto.

En tal sentido, como parte de dicho proceso, doña Pastora deja ver en sus respuestas esa nueva actitud hacia la lengua, motivada por las acciones que los gobiernos han emprendido con diversas actividades hacia la lengua. Sin embargo, los criterios sobre cómo son percibidos hoy en día los hablantes de maya en Mérida se representan en puntos de vista heterogéneos. Esto lo ilustraremos con el caso de Enrique y Josué, dos informantes jóvenes que expresan perspectivas opuestas que podemos observar en la siguiente tabla, según las frases que enunciaron sobre el tema: 


\begin{tabular}{|l|l|}
\hline \multicolumn{1}{|c|}{ Enrique: favorable ser mayahablante } & \multicolumn{1}{|c|}{ Josué: desfavorable ser mayahablante } \\
\hline $\begin{array}{l}\text {-Muchos querían que yo les enseñara } \\
\text { maya, es algo nuevo para ellos. } \\
\text {-La gente de Mérida dice que es muy } \\
\text { bonito que uno sepa hablar maya, así no } \\
\text { te engañan. }\end{array}$ & $\begin{array}{l}\text {-Cuando te ven hablando maya te humillan, } \\
\text { te dicen que eres de pueblo. }\end{array}$ \\
$\begin{array}{l}\text {-El inglés también es bonito, igual la maya, } \\
\text { aunque hables español debes aprender un } \\
\text { poco. }\end{array}$ & $\begin{array}{l}\text {-A algunas personas les da verguienza que } \\
\text {-Así hay unas personas que te van hablar } \\
\text { en maya. }\end{array}$ \\
$\begin{array}{l}\text {-Estamos perdiendo lo que es nuestro } \\
\text { idioma. } \\
\text {-Nuestro idioma es maya. } \\
\text {-Mayormente la maya se habla porque } \\
\text { somos de Yucatán. }\end{array}$ & $\begin{array}{l}\text {-Los de Mérida nos ven como si fuéramos } \\
\text { de otra categoría. }\end{array}$ \\
& $\begin{array}{l}\text {-Aquí en Mérida casi no se habla la maya, } \\
\text { mayormente puro español. }\end{array}$ \\
\hline
\end{tabular}

Tabla 2. Dos visiones juveniles opuestas de bilingües de maya y español.

Enrique, de 19 años, señala que en la capital yucateca tiene prestigio saber la lengua maya; mientras que Josué, de 18 años, piensa todo lo contrario. El primero expresa una visión positiva sobre sí mismo como hablante del idioma, en tanto que el segundo sostiene los puntos de vista más negativos. Tenemos entonces dos actitudes disímiles, y resulta importante plantearse el porqué de ello.

En nuestra interacción con Enrique, éste nos compartió que actualmente realiza estudios de licenciatura, motivo principal de su estancia en Mérida, además señaló que se ha desempeñado como obrero en diversas fábricas, donde sintió que sus compañeros lo reconocían por saber la lengua maya. Por su parte, Josué no estaba realizando ninguna actividad en el momento de la entrevista, ni estudios, ni trabajo. Lo abordamos en un parque y comentó que estaba "haciendo tiempo" para ir a buscar a un empleador de albañiles, ya que es la actividad que él conoce, pero no se encontraba entusiasmado y tampoco seguro de conseguir algo de trabajo. Además, nos confió sus dificultades económicas para costear los estudios de bachillerato que le gustaría realizar.

Por lo anterior, el contexto socioeconómico de ambos, entre muchos otros factores, genera dos visiones opuestas. Además, la idea de Josué acerca de que la gente de Mérida ve a los mayas como de otra categoría es un punto de vista que puede estar sostenido en sus impresiones; por su parte, Enrique, cuando menciona que muchos querían que él les enseñara maya, es porque en su experiencia laboral la gente con la que ha estado le ha pedido que les diga cómo se 
dicen algunas palabras en maya, lo que para él es un orgullo como mayahablante. Claramente el contexto donde se sitúen los hablantes de maya y español tiene mucho peso al momento de la interacción.

\section{Conclusiones}

Nuestra primera pregunta de investigación - icuáles son las actitudes de los yucatecos bilinguies de maya y español de la ciudad de Mérida hacia la maya y hacia los propios hablantes bilinguies? - puede responderse de la siguiente manera: los hablantes como endogrupo perciben actitudes sociales predominantemente positivas hacia la lengua y hacia ellos mismos ${ }^{10}$ de parte del exogrupo (los no mayahablantes de su contexto), que contrastan con actitudes negativas del pasado. Sin embargo, también parecen otorgarle poco prestigio a la variedad que hablan, el xe'ek' maya, dado que consideran que carece de legitimidad frente a la hach maya.

Para responder a nuestra segunda pregunta - ¿por qué se han modificado las actitudes de los yucatecos bilinguies de maya y español?- diremos que el cambio hacia actitudes positivas se debe con mucha probabilidad a las políticas públicas encaminadas a incrementar el estatus de la lengua, así como quizá al fenómeno mediático mundial generado por el fin del Baktún, en 2012.

Es interesante considerar los casos de Enrique y Josué a la luz de los hallazgos contrastantes de Mossbrucker (1992) en el sentido de que han desaparecido las distinciones socioétnicas en la identidad yucateca, así como de Iturriaga Acevedo (2011), quien muestra la persistencia de actitudes racistas hacia los mayas y las clases sociales bajas por parte de las élites meridanas. En los casos de estos dos jóvenes, las actitudes diferenciadas parecen estar conectadas con aspectos de la identidad social de los hablantes bilinguies. Respecto a Enrique, la percepción de actitudes positivas hacia él como mayahablante puede estar ligada a su identidad social de estudiante universitario, la cual posiblemente le confiere un estatus distinto entre sus compañeros de trabajo. En contraste, las actitudes negativas que percibe Josué pueden responder a su bajo nivel socioeconómico y ocupación carente de prestigio. Esta interpretación es consonante con el hecho de que las actitudes negativas de los miembros de las élites hacia las personas de fenotipo amerindio son mitigadas por la presencia de indicadores identitarios relacionados con la clase media como la ropa, el aseo personal, el tipo de ocupación y el nivel educativo que éstos señalan (Iturriaga Acevedo, 2011).

Pudiera pensarse que, al adscribirse la población mayahablante que participó en este estudio a los estratos socioeconómicos bajos, sus experiencias serían

\footnotetext{
${ }^{10}$ Por el contrario, Josué, como observamos en la manifestación de su testimonio líneas arriba, dice que persisten actitudes negativas hacia la lengua y los hablantes.
} 
similares a las de Josué. Sin embargo, los otros participantes del estudio no mostraron una relación clara entre sus marcadores identitarios y las actitudes que perciben. Es posible que, como sostiene Castellanos Guerrero (2003) en su crítica a Mossbrucker (1992), los casos de actitudes discriminatorias se callen por dignidad propia. Pero esto no puede afirmarse, por lo que se requieren más estudios con muestras más amplias e instrumentos distintos para determinar la posible influencia de otros factores identitarios en las actitudes positivas o negativas hacia los hablantes bilinguies.

Apoyándonos en el caso de Josué, las evidencias de actitudes racistas hacia los meridanos de fenotipo distinto al europeo encontradas por Iturriaga Acevedo (2011), las actitudes negativas hacia los hablantes monolingües mayas encontradas por Sima Lozano (2012) y el continuo desplazamiento de la lengua maya (INEGI, 2005, 2010, 2011), sugerimos que el estatus renovado del que goza la lengua maya en Yucatán, debido a las políticas públicas, no se ha extendido de manera uniforme a los hablantes. Tanto los yucatecos bilinguies de maya y español, y los monolingües de español de la capital yucateca dicen cosas maravillosas del idioma maya, pero no siempre del hablante bilinguie de maya y español, y ciertamente no del monolingüe maya. Por estas razones, consideramos importante ampliar el estudio, donde no sólo se indague cuáles son las actitudes hacia la lengua sino también hacia el hablante maya en el contexto peninsular yucateco, pues éstas no son las mismas entre la lengua y el hablante.

Una posible explicación muy tentativa de esta diferencia entre las actitudes hacia la lengua y los hablantes puede encontrarse en la confrontación de varios discursos en el contexto meridano contemporáneo. Por un lado, las políticas públicas que revaloran la lengua pueden enmarcarse dentro de un discurso de respeto a la diversidad cultural indígena que ha cobrado fuerza en México desde el levantamiento zapatista y se ha expresado vigorosamente en muchos países latinoamericanos. Dicho levantamiento fue construido desde abajo, en contraste con el caso del ser maya en Yucatán, que fue cimentándose desde arriba por los intereses y la oportunidad que vieron las instancias gubernamentales por figurar en el tema.

Asimismo, el racismo y la valoración negativa del hablante, quien es fenotípicamente amerindio antes que mestizo o europeo, puede explicarse por dos discursos racistas. Uno es el racismo persistente y característico de las élites meridanas; otro es el discurso consumista de la globalización que privilegia el fenotipo europeo sobre todos los demás y lo conecta con un imaginario de sofisticación: la modernidad en Latinoamérica se representa, se vive y se imagina desde y hacia la blancura (Bonnett, 2002). La desaparición o atenuación del racismo estructural (Wieviorka, 1998) es necesaria para la movilidad social de los mayahablantes y ha sucedido en alguna medida en Yucatán (Gabbert, 1997). Sin embargo, la marginación del amerindio, en general, y el maya, en particular, en los medios habla de la persistencia de un racismo simbólico (Wieviorka, 1998) que no necesariamente desaparece con la atenuación del racismo estructural. 
Como ello no asegura una expansión y un fomento hacia la lengua, ante esta situación el Estado podría intervenir más vigorosamente para fomentar la revaloración del mayahablante mediante políticas de inclusión que aseguren la representación igualitaria de diversos grupos fenotípicos en los medios y en la publicidad privados, como se hace en los Estados Unidos por ejemplo. Una forma más indirecta de fomentar actitudes positivas hacia los hablantes sería promover la expansión de la maya a más dominios funcionales además de los actuales, que comprenden noticieros y clases opcionales en algunas escuelas primarias, como ya se hace, pero de manera incipiente.

Finalmente, anotamos que en el futuro será necesario realizar más estudios desde diversas perspectivas metodológicas para examinar si las políticas que han tenido éxito en elevar el estatus de la lengua maya, que son relativamente recientes, alcanzan a favorecer el mantenimiento de dicha lengua y el estatus de sus hablantes en los años venideros. El futuro de la maya está en manos de sus hablantes y de la sociedad en la que estos viven, y las actitudes de ambos indudablemente serán decisivas para su permanencia en el tiempo.

\section{BIBLIOGRAFÍA}

Ager, Dennis

2001 Motivation in Language Planning and Language Policy. Clevedon / Buffalo / Toronto / Sydney: Multilingual Matters.

Alvarez Murillo, Edna

2008 "Estudio de actitudes linguiísticas maya-español a través del análisis del discurso en Holcá, Yucatán”, tesis de maestría en Antropología. México: Universidad Nacional Autónoma de México, Facultad de Filosofía y Letras / Instituto de Investigaciones Antropológicas.

Arzápalo Marín, Ramón

1997 "Las políticas linguíísticas en la zona del maya yucateco: cuestiones éticas de las interrelaciones sociales”, Políticas lingüísticas en México, Beatriz Garza Cuarón (coord.). México: Universidad Nacional Autónoma de México, Centro de Investigaciones Interdisciplinarias en Ciencias y Humanidades, pp. 217-228.

Barragán Trejo, Daniel

2006 "Si no lo haces, ¿de qué vives? Migrantes mi’pháá (tlapanecos de Tlacoapa) en Tlaquepaque: un desplazamiento linguíístico en proceso", tesis de maestría en Linguiística Aplicada. Guadalajara: Universidad de Guadalajara.

2009 "Si no la haces, ¿de qué vives? Le vamos a enseñar poco tlapaneco": Un desplazamiento linguiístico en proceso entre migrantes mi'phaa (tlapanecos de Tlacoapa) en Tlaquepaque, Jalisco, México", Cuadernos Interculturales, 7 (12): 21-46. Chile: Universidad de Valparaíso. 
Be Ramírez, Pedro Antonio

2011 "Dimensiones culturales e identidades situadas: la herencia maya en migrantes yucatecos a Estados Unidos”, Estudios de Cultura Maya, XXXVIII, (otoño-invierno): 167-192. México: Universidad Nacional Autónoma de México, Instituto de Investigaciones Filológicas, Centro de Estudios Mayas.

Bonnet, Alastair

2002 "A White World? Whiteness and the Meaning of Modernity in Latin America and Japan". Working through whiteness: International perspectives, Cynthia Levine Rasky (coord.). Albany, Estados Unidos: Universidad Estatal de Nueva York, pp. 69-106.

Bouchard Ryan, Ellen, Howard Giles y Richard Sebastian

2000 "Una perspectiva integrativa para el estudio de actitudes hacia la variación linguiística”, Estudios de Sociolingüística, Yolanda Lastra (comp.). México: Universidad Nacional Autónoma de México, Instituto de Investigaciones Antropológicas, pp. 491-511.

Briceño Chel, Fidencio

2010 "La maya, lo maya, un maya: Lengua, cultura e identidad de un pueblo", conferencia presentada en el Festival de la Mayanidad, 26 y 27 de agosto en Mérida, Universidad Autónoma de Yucatán, 15 pp. <http://www.proindigenas.org/attachments/article/26/fbc_lamaya_lomaya_elmaya_082010.pdf >. [Consultado el 8 de enero de 2013.]

2012 "Sólo el 2\% de los mayas de 5 a 9 años en Yucatán habla su lengua", Zócalo, Saltillo, México <http://www.zocalo.com.mx/seccion/articulo/solo-2-deninos-mayas-habla-su-lengua $>$. [Consultado el 6 de marzo de 2013.]

Bright, William

2000 "Cosas que la gente sabe sobre la lengua pero que no son así", Estudios de Sociolingüística, Yolanda Lastra (comp.). México: Universidad Nacional Autónoma de México, Instituto de Investigaciones Antropológicas, pp. 49-59.

Canché Teh, Flor, Barbara Pfeiler y Carlos Carrillo Carreón

2010 "La familia extensa como promotora de la vitalidad del maya", Etnia, lengua y territorio El sureste ante la globalización, Ricardo López Santillán (coord.). Mérida: Universidad Nacional Autónoma de México, Centro Peninsular en Humanidades y Ciencias Sociales, pp. 237-250.

Castañeda, Quetzil E.

2004 “ “iNo somos indígenas!' Una introducción a la identidad maya de Yucatán”, Estrategias identitarias. Educación y la antropología histórica en Yucatán, Juan A. Castillo Cocom y Quetzil E. Castañeda (eds.). Mérida: Universidad Pedagógica Nacional / The Open School of Etnography and Anthropology (OSEA) / Secretaría de Educación Pública, pp. 1-32.

Castellanos Guerrero, Alicia

2003 "Imágenes racistas en ciudades del sureste", Imágenes del racismo en México, 
Alicia Castellanos Guerrero (coord.). México: Universidad Autónoma de México / Plaza y Valdés, pp. 35-142.

Castillo Hernández, Mario Alberto

2007 Mismo mexicano pero diferente idioma: Identidades y actitudes lingüísticas en los maseualmej de Cuetazalan. México: Universidad Nacional Autónoma de México, Instituto de Investigaciones Antropológicas.

Cazés, Daniel

1990 "Las categorías de opresión étnica y opresión linguiística”, IV parte Estudios sobre las lenguas de México y España, Violeta Demonte y Beatriz Garza Cuarón (eds.). México: Universidad Nacional Autónoma de México / Colegio de México, pp. 587-601.

Duran Caballero, José Enrique y Julio Enrique Sauma Castillo

2003 "Actitudes hacia la enseñanza de la lengua maya en el municipio de Mérida, Yucatán: Un estudio desde la perspectiva de la Sociología del lenguaje”, tesis de licenciatura en Antropología. Mérida: Universidad Autónoma de Yucatán.

Fishman, Joshua

1974 "Conservación y desplazamiento del idioma como campo de investigación (Reexamen)", Antología de Estudios de etnolingüística y sociolingüística, Paul Garvin y Yolanda Lastra (coords.). México: Universidad Nacional Autónoma de México, Instituto de Investigaciones Antropológicas, pp. 375-423.

1979 Sociología del lenguaje. Madrid: Ediciones Cátedra.

1991 Reversing Language Shift. Theoretical and Empirical Foundations of Assistance to Threatened Languages. Clevedon: Multilingual Matters Ltd.

Gabbert, Wolfgang

1997 “¿Integración o colonialismo interno? Cultura y desigualdad en Yucatán”, Yucatán a través de los siglos. Memorias del $49^{\circ}$ Congreso Internacional de Americanistas, Quito, Ecuador, Ruth Gubler y Patricia Martel (comps.). Mérida: Universidad Autónoma de Yucatán, pp. 261-284.

Hamel, Enrique y Héctor Muñoz

1988 "Desplazamiento y resistencia de la lengua otomí: el conflicto linguiístico de las prácticas discursivas y la reflexividad", Sociolingüística latinoamericana $X$ Congreso Mundial de Sociología, México 1982, Rainer Enrique Hamel, Yolanda Lastra de Suárez y Héctor Muñoz Cruz (eds.). México: Universidad Nacional Autónoma de México, pp. 101-146.

Hernández Méndez, Edith y Eyder Gabriel Sima Lozano

En dictamen "El español en contacto con el maya y el inglés en la Península de Yucatán", Lengua española, contacto lingüístico y globalización, México: Universidad Nacional Autónoma de México, Centro de Enseñanza de Lenguas Extranjeras.

Hernández Sampieri, Roberto, Carlos Fernández Collado y Pilar Baptista Lucio

2006 Metodología de la investigación. México: McGrawHill. 
Instituto Nacional de Estadística y Geografía

2005 "Il conteo de población y vivienda 2005 Perfil Sociodemográfico de Yucatán” <http://www.inegi.org.mx/prod_serv/contenidos/espanol/bvinegi/ productos/censos/conteo/2005/perfiles/PS_YUC_1.pdf>. [Consultado el 3 de marzo de 2013.]

2010 "Cuéntame información por entidad Yucatán" <http://cuentame.inegi.org.mx/ monografias/informacion/yuc/poblacion/diversidad. aspx?tema $=$ me $\& \mathrm{e}=31>$. [Consultado el 6 de marzo de 2013.]

2011 "Panorama sociodemográfico de Yucatán" <http://www.inegi.org.mx/prod_ serv/contenidos/espanol/bvinegi/productos/censos/poblacion/2010/panora_ socio/yuc/Panorama_Yuc.pdf $>$. [Consultado el 5 de septiembre de 2013.]

Instituto Nacional de Lenguas Indígenas

2008 "Catálogo de las Lenguas Indígenas Nacionales: Variantes Linguiísticas de México con sus autodenominaciones y referencias geoestadística" $<\mathrm{http}: / /$ www.inali.gob.mx/pdf/CLIN_completo.pdf $>$. [Consultado el 01 de marzo de 2013.]

Iturriaga Acevedo, Eugenia

2011 "Las élites de la ciudad blanca: racismo, prácticas y discriminación étnica en Mérida, Yucatán”, tesis de doctorado en Antropología. México: Universidad Nacional Autónoma de México, Facultad de Filosofía y Letras.

Jiménez Peraza, Pedro César

1982 Lealtad hacia la lengua maya, México: Secretaría de Educación Pública / Instituto Nacional Indigenista.

López Santillán, Ricardo

2011 Etnicidad y clase media. Los profesionistas mayas residentes en Mérida. Mérida y México: Universidad Nacional Autónoma de México / Instituto de Cultura de Yucatán / Consejo Nacional para la Cultura y las Artes.

McConnell, Grant

1991 A Macro-Sociolinguistic Analysis of Language Vitality: Geolinguistic Profiles and Scenarios of Language Contact in India. Sainte-Foy: Les presse de L'Université Laval.

Mossbrucker, Harald

1992 "Etnia, cultura y el impacto de la migración entre los mayas de Yucatán”, América Indígena, LII (4): 187-214, octubre-noviembre. México: Instituto Indigenista Interamericano.

2001 Cultura y etnicidad en Yucatán: conceptos generales y situaciones específicas. Hannover / Guatemala: Verlag für Ethnologie (Colección Americana, 3).

Neri, Lourdes

2011 "El desplazamiento de la lengua totonaca en la comunidad de Mecapala, Pantepec, Puebla", Muerte y vitalidad de las lenguas indígenas y las presiones sobre sus hablantes, Roland Terborg y Laura García Landa (coords.). México: 
Universidad Nacional Autónoma de México, Centro de Enseñanza de Lenguas Extranjeras, pp. 151-175.

Pfeiler, Bárbara

1993 "La lealtad linguíística del indígena maya yucateco. Validación de la prueba de matched-guise", Estudios de Lingüística Aplicada, 11 (17): 82-93. México: Universidad Nacional Autónoma de México, Centro de Enseñanza de Lenguas Extranjeras.

1997 "El maya: una cuestión de persistencia o pérdida cultural", Persistencia cultural entre los mayas frente al cambio y la modernidad, Ramón Arzápalo Marín y Ruth Gubler (comps.). Mérida: Universidad Autónoma de Yucatán, pp. 5577.

1998 "El Xe'ek y la Hach Maya: cambio y futuro del maya ante la modernidad cultural en Yucatán”, Convergencia e identidad. Las lenguas mayas entre hispanización e indigenismo, Andreas Koechert y Thomas Stolz (eds.). Hannover: Verlag für Etnologie (Colección Americana, 7), pp. 125-140.

1999 "Investigación y preservación de la lengua maya (yucateca). Propuesta de un programa”, Interculturalidad e Identidad Indígena. Preguntas abiertas a la globalización en México, Andreas Koechert y Bárbara Pfeiler (eds.). Hannover: Verlag für Ethnologie (Colección Americana, 4), pp. 295-303.

Pfeiler, Bárbara y ZámiŠová, Lenka

2006 "Bilingual educaction: Strategy for language maintenance of shift of Yucatec Maya?", Mexican Indigenous Languages at the Dawn of the Twenty-First Century. Contributions to the Sociology of Language, Margarita Hidalgo (ed.). BerlínNew York: Mouton de Gruyter, pp. 281-301.

Rico Lemus, Gabriel

2011 "Resistencia y mantenimiento de la lengua p’urhépecha en Santa Fe de la Laguna, Michoacán", Muerte y vitalidad de las lenguas indígenas y las presiones sobre sus hablantes, Roland Terborg y Laura García Landa (coords.). México: Universidad Nacional Autónoma de México, Centro Enseñanza de Lenguas Extranjeras, pp. 119-152.

Rodríguez, Edgar

2000 Mérida sin arrebol. Mérida: Consejo Nacional para la Cultura y las Artes / Fondo Nacional para la Cultura y las Artes / Maldonado Editores del Mayab.

Sánchez Arroba, María Elena

2009 "Migración y pérdida de la lengua maya en Quintana Roo", Migración y políticas públicas, M. Saúl Vargas Paredes (coord.). México: Cámara de Diputados / Universidad de Quintana Roo / Miguel Ángel Porrúa, pp. 397-468.

Silva-Corvalán, Carmen

2001 Sociolingüística y pragmática del español. Washington, D.C: Georgetown University Press. 
Sima Lozano, Eyder Gabriel

2010 "Actitudes hacia la maya en el contexto de enseñanza en 2 escuelas primarias de la ciudad de Mérida", ponencia presentada en el IV Simposio sobre Política del lenguaje del 27 al 29 de octubre. Mérida: Universidad Nacional Autónoma de México, Centro Peninsular en Humanidades y Ciencias Sociales.

2011 "Actitudes de monolinguies de español hacia la maya y sus hablantes en Mérida”, Ketzalcalli, 2: 61-80. Mérida: Universidad de Quintana Roo / Universidad de Hamburgo / Universidad Nacional Autónoma de México.

2012 "Actitudes hacia la lengua maya de un sector de población de la ciudad de Mérida”, tesis de doctorado en Antropología. México: Universidad Nacional Autónoma de México, Facultad de Filosofía y Letras, Instituto de Investigaciones Antropológicas.

Terborg, Roland y Laura García Landa

2011 "Las presiones que causan el desplazamiento-mantenimiento de las lenguas indígenas. La presentación de un modelo y su aplicación”, Muerte y vitalidad de las lenguas indígenas y las presiones sobre sus hablantes, Roland Terborg y Laura García Landa (coords.). México: Universidad Nacional Autónoma de México, Centro de Enseñanza de Lenguas Extranjeras, pp. 29-61.

Trujillo Tamez, Isela

2011 "Situación sociolinguiística del mixe en San Lucas Camotlán”, Muerte y vitalidad de las lenguas indígenas y las presiones sobre sus hablantes, Roland Terborg y Laura García Landa (coords.). México: Universidad Nacional Autónoma de México, Centro de Enseñanza de Lenguas Extranjeras, pp. 89-117.

Villanueva, Nancy

2008 "La revaloración de la cultura maya en Yucatán”, Temas Antropológicos, 30 (2): 79-108. Mérida: Universidad Autónoma de Yucatán, Facultad de Ciencias Antropológicas.

Wieviorka, Michel

1998 Le racisme: une introduction. Paris: La Découverte y Syrus.

Zimmermann, Klaus

1999 Política del lenguaje y planificación para los pueblos amerindios. Ensayos de ecología lingüística. Madrid / Frankfurt: Iberoamericana / Vervuert. 
